\title{
Comparative Study on Microorganisms Used for the Bioethanol Production
}

\author{
Corina Amalia Macarie ${ }^{1}$, Adina-Elena Segneanu' ${ }^{1}$, Ionel Balcu ${ }^{1}$, Raluca Pop ${ }^{1}$, Georgeta Burtica ${ }^{2}$, \\ Vasile-Daniel Gherman ${ }^{2}$ \\ ${ }^{1}$ National Institute for Research and Development in Electrochemistry and Condensed Matter, Timisoara, Romania; ${ }^{2}$ The Faculty of \\ Civil Engineering, Politehnica University of Timisoara, Timisoara, Romania. \\ Email: s-adinaelena@yahoo.com
}

Received September $2^{\text {nd }}, 2011$; revised October $10^{\text {th }}, 2011$; accepted October $17^{\text {th }}, 2011$.

\begin{abstract}
Two different methods, namely simultaneous saccharification and fermentation and two-stage hydrolysis and fermentation have been used for the conversion of the cellulose into bioethanol. Both aerobic and anaerobic conditions were employed in order to obtain two types of microorganisms - Trichoderma reesei and Zymomonas mobilis—that are used for the production of cellulases. The aim of the paper is to investigate also the efficiency of a microorganism's consortium in the fermentation stage of the two processes and the action of this microorganism's consortium on different concentrations of the cellulosic substrate, in order to determine the optimum parameters of the process. Good yields (45\% 70\%) of the cellulose degradation into fermentable sugars have been obtained.
\end{abstract}

Keywords: Bioethanol, Lignocellulosic Biomass, Microorganism

\section{Introduction}

Due to the limitations of fossil energy, there is a continuous increasing interest in finding new alternatives for oil-based fuels. Renewable resources like sugarcane or agricultural crops have represented the major raw materials for the bioethanol production [1]. In the last years, lignocellulosic materials have gained much importance for the obtaining of bioethanol, mostly due to their large availability. The main disadvantage is represented by the higher costs caused by the small yields and by the difficulties encountered in the cellulose hydrolysis (deploymerization) in soluble sugars [2,3].

Chemical methods for the depolymerization of the cellulose are the acid, basic or enzymatic hydrolysis. Among them, enzymatic hydrolysis shows the advantages of mild reactions conditions and of avoiding the corrosion problems [4-7].

Cellulose transformation into soluble sugars during the enzymatic hydrolysis process occurs by the means of cellulase, an enzyme with a high cost of production. Lately, in the biofuels industry, cellulases obtained from the Trichoderma reesei fungus are used, with good results regarding the vegetal feedstock degradation $[8,9]$. This could enlarge the possible biomass resources. Another microorganism used for the bioethanol production is Zymomonas mobilis that may be used only for substrates that contain glucose, fructose and sucrose [10-12].

There are two main procedures used for the bioethanol production starting from cellulose. The first one implies two different stages, namely the hydrolysis of the cellulosic substrate, followed by the fermentation of the obtained sugars. The second method implies the simultaneous saccharification and fermentation $[10,13,14]$.

The present paper presents the cellulose degradation under the action of Trichoderma reesei and Zymomonas mobilis, in order to determine the optimum conditions for the bioethanol production through the hydrolysis and fermentation of cellulose-based materials. The hydrolysis of the cellulosic substrate was performed using Trichoderma reese $i$, and for the separate fermentation of sugars there were used enzymes from Zymomonas mobilis. For the simultaneous saccharification and fermentation of a cellulosic substrate a consortium of the two microrganisms was employed. The results of the two fermentation methods (separate and simultaneous) have been quantified by means of the concentration of the unreacted fermentable sugars that were not transformed into ethanol.

\section{Experimental Part}

Lyophilized strains of Trichoderma reesei (IHEM 5652) 
and Zymomonas mobilis (ATCC 29191) were used, that were reactivated at their transfer on the culture media.

\subsection{The Obtaining of Cellulose and Hemicellulose Degrading Enzymes from Micro-Organism Cultures}

Cellulases from Trichoderma reesei and Zymomonas mobilis.

The cultures were incubated for several days at a temperature of $30^{\circ} \mathrm{C}$, without shaking, both in anaerobic and aerobic conditions. At various time intervals samples were taken in order to analyze the cellulase activity on the substrate (carboxymethylcellulose standard) and also for the determination of the protein content.

\subsection{Cellulose Degradation by Enzymes Obtained from Trichoderma reesei}

The Trichoderma strains were inoculated on a natural culture medium that contained $100 \mathrm{~mL}$ potato extract, $2 \mathrm{~g}$ glucose and 0.5 g, 0.75 g, 1.0 g, 1.5 g and 2.0 g Avicel, respectively. The cultures were sterilized in an autoclave, inoculated and thermostated for several days at $30^{\circ} \mathrm{C}$. Samples of a few milliliters were taken in order to determine the total sugar content.

\subsection{Sugar Fermentation by Enzymes from Zymomonas mobilis}

Cultures of Zymomonas in a synthetic medium were used. The synthetic culture medium was made by $0.5 \mathrm{~g}$ yeast extract, $0.1 \mathrm{~g}\left(\mathrm{NH}_{4}\right)_{2} \mathrm{SO}_{4}, 0.2 \mathrm{~g} \mathrm{~K}_{2} \mathrm{HPO}_{4}, 0.1 \mathrm{~g} \mathrm{MgSO}_{4}$ and $2.0 \mathrm{~g}, 4.0 \mathrm{~g}, 6.0 \mathrm{~g}$ and $8.0 \mathrm{~g}$ glucose, respectively. The cultures were syntetized by the same way like in case of Trichoderma reesei strains.

\subsection{Cellulose Degradation by Enzymes Obtained from Trichoderma reesei and Zymomonas mobilis}

Cultures of Trichoderma and Zymomonas on natural medium were used. The natural culture medium contained $100 \mathrm{~mL}$ potato extract, 2 g glucose and $1.0 \mathrm{~g}, 1.5 \mathrm{~g}, 2.0 \mathrm{~g}$, $3.0 \mathrm{~g}$ and $4.0 \mathrm{~g}$ Avicel, respectively. Sterylization procedure of cultures is identical with the previous method.

\subsection{Determination of the Total Sugar Content}

The total sugar content was calculated using the colorimetric method for the determination of the reducing sugars with the DNS (3,5-dinitrosalycilic acid) reagent. In order to calculate the total sugar content, Equation (1) was used.

$$
\begin{aligned}
& \text { Total sugars } \\
& =\left[\left(\mathrm{A}_{540}+0.07447\right) / 1.22612\right] \times \text { dilution factor }
\end{aligned}
$$

where, $\mathrm{A}_{540}$-solution absorbance (extinction) at $540 \mathrm{~nm}$ dilution factor-5.

The calibration curve used for the determination of the total sugar content (as glucose) is presented in Figure 1.

\section{Results and Discussions}

The total protein content obtained from cultures of Trichoderma reesei and Zymomonas mobilis both in anaerobic and aerobic is presented in Figures 2-3 and Tables 1-2.

The protein content in aerobic and anaerobic conditions has been determined from the influence of the concentration of oxygen on the development of Trichoderma reesei and Zymomonas mobilis.

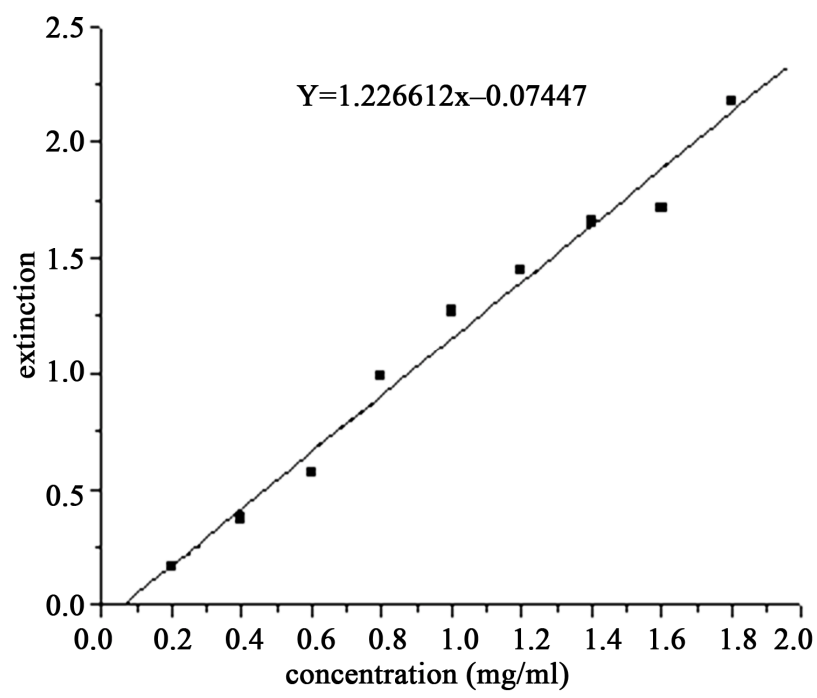

Figure 1. Glucose calibration curve using the colorimetric method (Correlation coefficient $R(2)=0.9908)$.

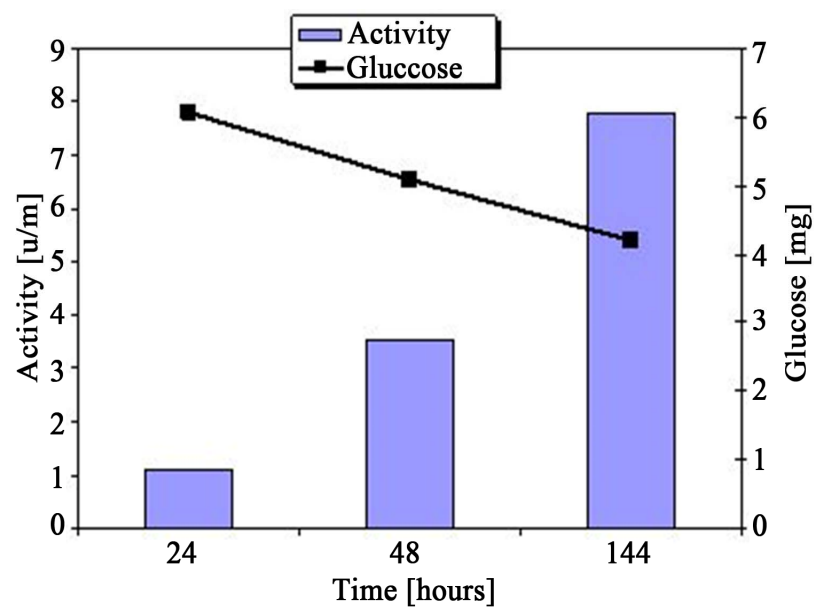

Figure 2. The evolution in time of the cellulase activity produced by Trichoderma reesei and of the amount of glucose obtained in anaerobic conditions. 
The cellulosic substrate degradation with the enzymes obtained from $T$. reesei was quantified by the determination of the sugar content of the culture medium at different times. The Zymomonas strains present less efficiently in aerobic conditions (Table 2) then in anaerobic conditions (Table 1), but in this case also, no cellulase was produced. We can conclude that it cannot be used to produce cellulase in the given, studied, conditions.

The results are presented in Table 2 and, in a graphic form, in Figure 3. As a comparison, the theoretical quantities that could be obtained from the cellulose degradation with a $100 \%$ yield were calculated (Table 3 ). Data from the Tables $\mathbf{3}$ and $\mathbf{4}$ were used for the calculation of the yield of the cellulose enzymatic hydrolysis to sugars, results that are presented in Table $\mathbf{4}$ and Figure 4.

As it may be observed, best results are obtained for the culture media with a low content of cellulose (higher values are obtained for the methods where an initial con-

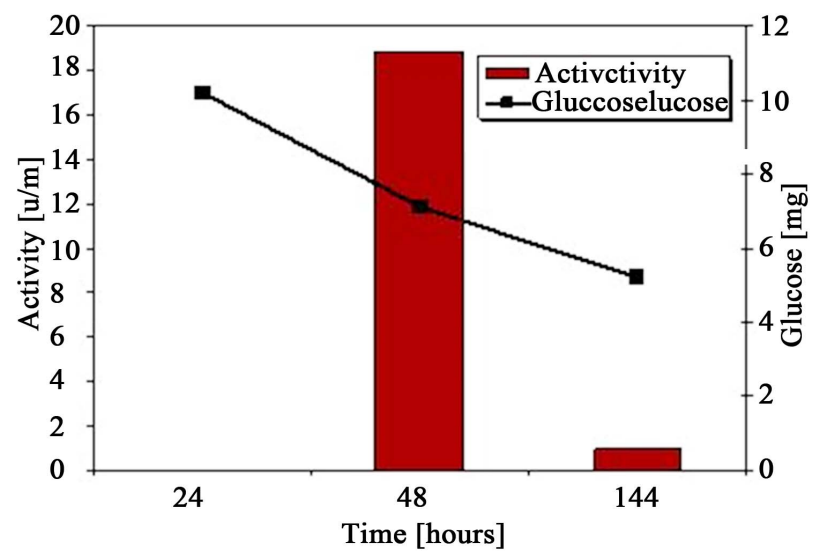

Figure 3. The evolution in time of the cellulase produced by Trichoderma reesei and of the amount of glucose obtained in aerobic conditions.

Table 1. The total protein content in Zymomonas mobilis cultures in anaerobic conditions.

\begin{tabular}{ccc}
\hline Time $[\mathrm{h}]$ & Carbon source & Protein $[\mathrm{mg} / \mathrm{ml}]$ \\
\hline 24 & & 0.971 \\
48 & Cellulose & 0.771 \\
144 & $5 \mathrm{~g} / \mathrm{L}$ & 0.918 \\
\hline
\end{tabular}

Table 2. The total protein content in Zymomonas mobilis cultures in aerobic conditions.

\begin{tabular}{ccc}
\hline Time $[\mathrm{h}]$ & Carbon source & Protein $[\mathrm{mg} / \mathrm{ml}]$ \\
\hline 24 & & 0.482 \\
48 & Cellulose $5 \mathrm{~g} / \mathrm{L}$ & 0.438 \\
144 & & 0.524 \\
\hline
\end{tabular}

Table 3. Maximum theoretical concentrations of total sugars and ethanol, considering maximum efficiency of the hydrolysis and fermentation processes.

\begin{tabular}{cccc}
\hline $\begin{array}{l}\text { No. of } \\
\text { culture }\end{array}$ & $\begin{array}{c}\text { Initial cellulose } \\
\text { concentration }(\mathrm{g} / \mathrm{L})\end{array}$ & $\begin{array}{c}\text { Theoretical sugars } \\
\text { concentration }(\mathrm{g} / \mathrm{L})\end{array}$ & $\begin{array}{c}\text { Theoretical ethanol } \\
\text { concentration }(\mathrm{g} / \mathrm{L})\end{array}$ \\
\hline 1 & 5 & 43.21 & 22.08 \\
2 & 7.5 & 45.41 & 23.21 \\
3 & 10 & 47.61 & 24.33 \\
4 & 15 & 52.01 & 26.58 \\
5 & 20 & 56.41 & 28.83 \\
\hline
\end{tabular}

Table 4. Results of the cellulose hydrolysis into fermentable sugars by means of enzymes obtained from Trichoderma reesei.

\begin{tabular}{|c|c|c|c|c|}
\hline $\begin{array}{l}\text { No. of } \\
\text { culture }\end{array}$ & $\begin{array}{l}\text { Initial cellulose } \\
\text { conc. }(\mathrm{g} / \mathrm{L})\end{array}$ & Time (h) & $\begin{array}{c}\text { Total sugars } \\
\text { concentration }(\mathrm{g} / \mathrm{L})\end{array}$ & $\begin{array}{l}\text { Sugars yield } \\
\text { (\%) }\end{array}$ \\
\hline \multirow{4}{*}{1} & \multirow{4}{*}{5} & 24 & 22.19 & 51.3 \\
\hline & & 48 & 24.84 & 57.5 \\
\hline & & 72 & 30.19 & 69.9 \\
\hline & & 96 & 28.17 & 65.2 \\
\hline \multirow{4}{*}{$2^{*}$} & \multirow{4}{*}{5} & 24 & 28.05 & 64.9 \\
\hline & & 48 & 29.60 & 68.5 \\
\hline & & 72 & 30.23 & 70.0 \\
\hline & & 96 & 28.20 & 65.3 \\
\hline \multirow{4}{*}{3} & \multirow{4}{*}{7.5} & 24 & 25.91 & 57.1 \\
\hline & & 48 & 28.08 & 61.8 \\
\hline & & 72 & 31.36 & 69.1 \\
\hline & & 96 & 29.87 & 65.8 \\
\hline \multirow{4}{*}{$4^{*}$} & \multirow{4}{*}{7.5} & 24 & 27.55 & 60.7 \\
\hline & & 48 & 26.12 & 57.5 \\
\hline & & 72 & 29.44 & 64.8 \\
\hline & & 96 & 29.11 & 64.1 \\
\hline \multirow{4}{*}{5} & \multirow{4}{*}{10} & 24 & 29.70 & 62.4 \\
\hline & & 48 & 28.08 & 59.0 \\
\hline & & 72 & 28.64 & 60.2 \\
\hline & & 96 & 31.01 & 65.1 \\
\hline \multirow{4}{*}{$6^{*}$} & \multirow{4}{*}{10} & 24 & 28.08 & 59.0 \\
\hline & & 48 & 23.35 & 49.0 \\
\hline & & 72 & 32.32 & 67.9 \\
\hline & & 96 & 28.89 & 60.7 \\
\hline \multirow{4}{*}{7} & \multirow{4}{*}{15} & 24 & 20.11 & 38.7 \\
\hline & & 48 & 19.83 & 38.1 \\
\hline & & 72 & 26.40 & 50.8 \\
\hline & & 96 & 23.74 & 45.6 \\
\hline \multirow{4}{*}{$8^{*}$} & \multirow{4}{*}{15} & 24 & 25.15 & 48.4 \\
\hline & & 48 & 23.53 & 45.2 \\
\hline & & 72 & 31.04 & 59.7 \\
\hline & & 96 & 30.49 & 58.6 \\
\hline \multirow{4}{*}{9} & \multirow{4}{*}{20} & 24 & 34.18 & 60.6 \\
\hline & & 48 & 30.85 & 54.7 \\
\hline & & 72 & 30.0 & 53.2 \\
\hline & & 96 & 31.13 & 55.2 \\
\hline \multirow{4}{*}{$10^{*}$} & \multirow{4}{*}{20} & 24 & 25.05 & 44.4 \\
\hline & & 48 & 25.18 & 44.6 \\
\hline & & 72 & 28.16 & 49.9 \\
\hline & & 96 & 29.54 & 52.4 \\
\hline
\end{tabular}

*There were used five cultures (in duplicate) of Trichoderma reesei. 


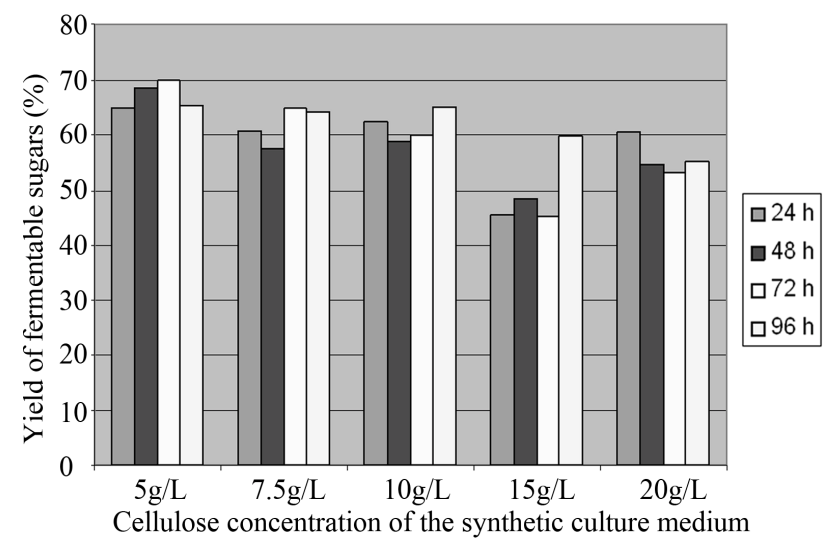

Figure 4. Yields of total sugars obtained from cellulose (best results of each duplicate culture are presented).

centration of $5 \mathrm{~g} / \mathrm{L}, 7.5 \mathrm{~g} / \mathrm{L}$ and $10 \mathrm{~g} / \mathrm{L}$ cellulose was used). The maximum yield of the cellulose in glucose transformation is $70 \%$ and it is obtained for a concentration of the cellulosic substrate of $5 \mathrm{~g} / \mathrm{L}$ and a reaction time of $72 \mathrm{~h}$. An increase of the reaction time leads (except the case of the substrate with the greatest cellulose content) to better results in concentrations of the fermentable sugars.

The fermentation process of the glucose using Zymomonas mobilis resulted in small amounts of unfermented sugars. Results presented in Table 5 and Figure 5 show that only small concentrations of unfermented sugars were obtained. It may also be observed that the best results are obtained during a longer reaction time (48 h - 96 h) and when shaking is applied.

Table 5 shows the untransformed sugar contents after the glucose fermentation in the presence of $Z$. mobilis and, starting from these experimental values, theoretical ethanol yield was calculated. The results presented in Figure 5 show that, independent from the substrate concentration, the best results are obtained after an enzyme action time of $72-96 \mathrm{~h}$.

A series of cellulosic substrates (Table 6) were subjected to the simultaneous action of Trichoderma reesei and Zymomonas mobilis for a 30 days period. The results are presented in Table 6 and Figure 6.

The results show no significant differences among the content of untransformed total sugars, independent of the initial cellulose concentrations. It appears that, in this case, higher initial concentrations of cellulose have positive influence on the total amounts of fermented sugars.

\section{Conclusions}

Trichoderma reesei cultures showed a lower growth of the microorganism under aerobic conditions than under anaerobic conditions. Cellulase was not detected after the first day, but after 48 hours it was formed in sufficiently
Table 5. The total sugar content experimentally resulted and the calculated theoretical ethanol concentration at sugars fermentation with Zymomonas.

\begin{tabular}{|c|c|c|c|c|}
\hline $\begin{array}{l}\text { No. of } \\
\text { culture }\end{array}$ & $\begin{array}{l}\text { Initial glucose } \\
\text { conc. }(\mathrm{g} / \mathrm{L})\end{array}$ & Time (h) & $\begin{array}{l}\text { Total sugars } \\
\text { conc. }(\mathrm{g} / \mathrm{L})\end{array}$ & $\begin{array}{l}\text { Theoretical ethanol } \\
\text { conc. (g/L) }\end{array}$ \\
\hline \multirow{4}{*}{$1^{*}$} & \multirow{4}{*}{20} & 24 & 2.21 & 9.09 \\
\hline & & 48 & 1.07 & 9.67 \\
\hline & & 72 & 0.45 & 9.99 \\
\hline & & 96 & 0.29 & 10.02 \\
\hline \multirow{4}{*}{2} & \multirow{4}{*}{20} & 24 & 0.23 & 10.10 \\
\hline & & 48 & 0.42 & 10.00 \\
\hline & & 72 & 0.46 & 10.00 \\
\hline & & 96 & 0.28 & 10.02 \\
\hline \multirow{4}{*}{$3^{*}$} & \multirow{4}{*}{40} & 24 & 2.17 & 19.33 \\
\hline & & 48 & 0.79 & 20.04 \\
\hline & & 72 & 0.72 & 20.08 \\
\hline & & 96 & 0.74 & 20.06 \\
\hline \multirow{4}{*}{4} & \multirow{4}{*}{40} & 24 & 0.35 & 20.26 \\
\hline & & 48 & 0.58 & 20.15 \\
\hline & & 72 & 0.43 & 20.22 \\
\hline & & 96 & 0.36 & 20.26 \\
\hline \multirow{4}{*}{$5^{*}$} & \multirow{4}{*}{60} & 24 & 0.89 & 30.21 \\
\hline & & 48 & 1.03 & 30.14 \\
\hline & & 72 & 1.03 & 30.14 \\
\hline & & 96 & 0.94 & 30.19 \\
\hline \multirow{4}{*}{6} & \multirow{4}{*}{60} & 24 & 2.29 & 29.50 \\
\hline & & 48 & 0.65 & 30.33 \\
\hline & & 72 & 0.62 & 30.35 \\
\hline & & 96 & 0.52 & 30.40 \\
\hline \multirow{4}{*}{$7^{*}$} & \multirow{4}{*}{80} & 24 & 2.80 & 39.50 \\
\hline & & 48 & 1.09 & 40.33 \\
\hline & & 72 & 1.47 & 40.14 \\
\hline & & 96 & 1.30 & 40.22 \\
\hline \multirow{4}{*}{8} & \multirow{4}{*}{80} & 24 & 2.17 & 39.78 \\
\hline & & 48 & 0.49 & 40.64 \\
\hline & & 72 & 0.46 & 40.65 \\
\hline & & 96 & 0.45 & 40.65 \\
\hline
\end{tabular}

*shaken at $150 \mathrm{rot} / \mathrm{min}$.

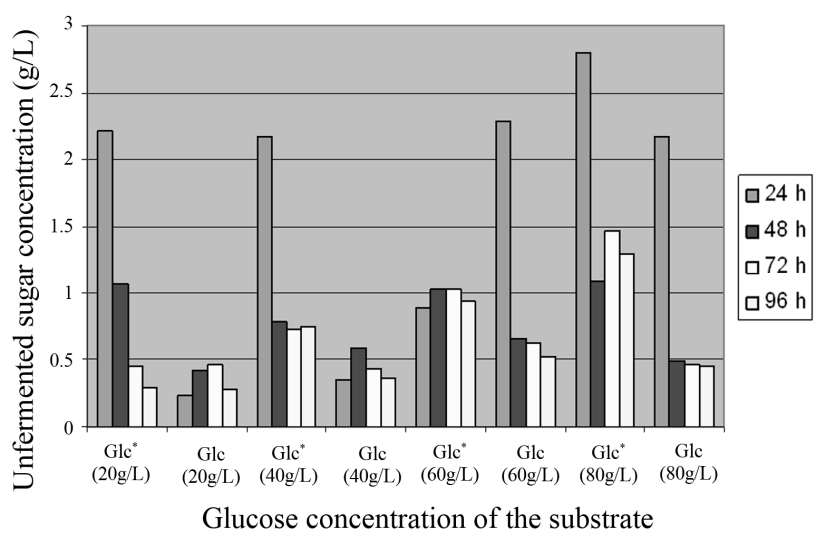

Figure 5. Total sugar content after glucose fermentation with Zymomonas mobilis. 
Table 6. The total sugar content at the action of a mixture of $T$. reesei and $Z$. mobilis on cellulosic substrates.

\begin{tabular}{ccccc}
\hline $\begin{array}{c}\text { No. of } \\
\text { culture }\end{array}$ & $\begin{array}{c}\text { Initial cellulose } \\
\text { conc. (g/L) }\end{array}$ & $\begin{array}{c}\text { Time } \\
\text { (days) }\end{array}$ & $\begin{array}{c}\text { Total sugar } \\
\text { content (g/L) }\end{array}$ & $\begin{array}{c}\text { Theoreticalethanol } \\
\text { conc. }(\mathrm{g} / \mathrm{L})\end{array}$ \\
\hline 1 & 10.0 & 30 & 1.077 & 23.78 \\
2 & 15.0 & 30 & 1.091 & 26.03 \\
3 & 20.0 & 30 & 1.110 & 28.77 \\
4 & 30.0 & 30 & 1.112 & 32.76 \\
5 & 40.0 & 30 & 1.065 & 37.28 \\
\hline
\end{tabular}

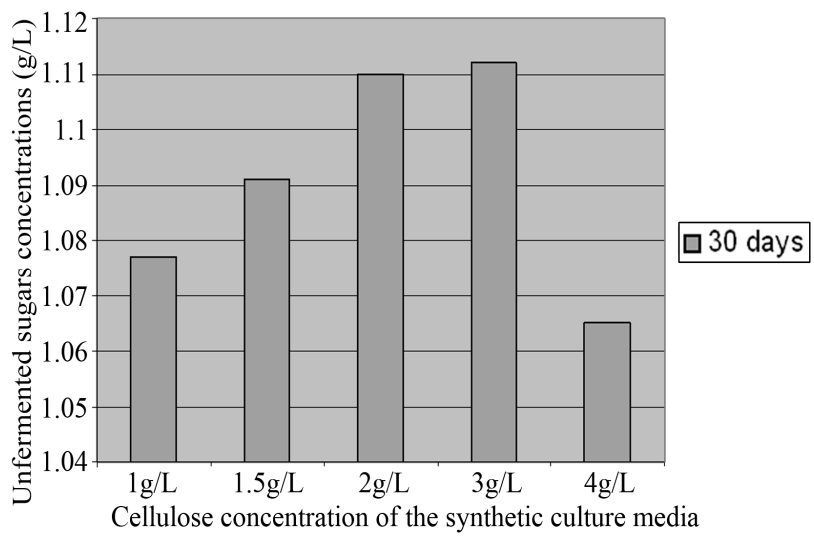

Figure 6. Total content of untransformed sugars after the action of a mixture of $T$. reesei and $Z$. mobilis.

large amounts. after 6 days, it disappeared almost completely from the medium. Cellulase can be also biosynthesised under aerobic conditions from Trichoderma reesei cultures, but it is very important to know the optimum time for stopping the culture if the cellulase activity is elevated. Zymomonas strain presented a lower growth under aerobic conditions than under the anaerobic ones, but cellulase was not produced in none of the cases. It may be said that the studied Zymomonas strain cannot produce cellulase in the culture media that were used in our experiments.

The results of the study show that $T$. reesei action on cellulose led to the obtaining of sugars (determined as glucose) in $45 \%$ - $70 \%$ yield. Higher content of sugars are obtained for an initial cellulose concentration of $5 \mathrm{~g} / \mathrm{L}$ - $10 \mathrm{~g} / \mathrm{L}$. Cellulose concentrations of $15 \mathrm{~g} / \mathrm{L}$ - $20 \mathrm{~g} / \mathrm{L}$ show an inhibitory effect on the cellulose degradation.

The experimental values of the total sugar content after the $Z$. mobilis action on glucose show that only small sugar amounts had not been transformed. Similar values of untransformed sugars are obtained after the action of a mixture of $T$. reesei and $Z$. mobilis on cellulosic substrates. As results from the values presented in Table 6 and Figure 6, higher cellulose concentration of the synthetic culture medium does not have negative consequences on the cellulose degradation process.

\section{REFERENCES}

[1] M. Balat, H. Balat and C. Oz, "Progress in Bio-Ethanol Processing," Progress in Energy and Combustion Science, Vol. 34, No. 5, 2008, pp. 551-573. doi:10.1016/j.pecs.2007.11.001

[2] F. Abd El-Zaher and M. Fadel, "Production of Bioethanol via Enzymatic Saccharification of Rice Straw by Cellulase Produced by Trichoderma reesei under Solid State Fermentation,” New York Science Journal, Vol. 3, 2010, p. 72.

[3] E. A. Bayer, R. Lamed and E. Himmel, "The Potential of Cellulases and Cellulosomes for Cellulosic Waste Management," Current Opinion in Biotechnology, Vol. 18, No. 3, 2007, pp. 237-245. doi:10.1016/j.copbio.2007.04.004

[4] H. Golias, G. J. Dumsday, G. A. Stanley and N. B. Pamment, "Evaluation of a Recombinant Klebsiella oxytoca Strain for Ethanol Production from Cellulose by Simultaneous Saccharification and Fermentation: Comparison with Native Cellobiose-Utilising Yeast Strains and Performance in Co-Culture with Thermotolerant Yeast and Zymomonas mobilis," Journal of Biotechnology, Vol. 96, No. 2, 2002, pp. 155-168. doi:10.1016/S0168-1656(02)00026-3

[5] S. Kumar, S. P. Singh, I. M. Mishra and D. K. Adhikari, "Recent Advances in Production of Bioethanol from Lignocellulosic Biomass,” Chemical Engineering \& Technology, Vol. 32, No. 4, 2009, pp. 517-526. doi:10.1002/ceat.200800442

[6] Y. Sun and J. Cheng, "Hydrolysis of Lignocellulosic Materials for Ethanol Production: A Review," Bioresource Technology, Vol. 83, No. 1, 2002, pp. 1-11. doi:10.1016/S0960-8524(01)00212-7

[7] H. C. Vogel and C. L. Todaro, "Fermentation and Biochemical Engineering Handbook," Noyes Publications, New Jersey, 1997.

[8] T. Fujii, X. Fang, H. Inoue, K. Murakami and S. Sawayama, "Enzymatic Hydrolyzing Performance of Acremonium cellulolyticus and Trichoderma reesei against Three Lignocellulosic Materials,” Biotechnology for Biofuels, Vol. 2, 2009, p. 24. doi:10.1186/1754-6834-2-24

[9] B. Nidetzky, W. Steiner, M. Hayn and M. Claeyssens, "Cellulose Hydrolysis by the Cellulases from Trichoderma reesei: Adsorptions of Two Cellobiohydrolases, Two Endocellulases and Their Core Proteins on Filter Paper and Their Relation to Hydrolysis,” Biochemical Journal, Vol. 298, 1994, p. 705.

[10] V. Ferreira, M. Faber, S. Mesquita and N. Pereira Jr., "Simultaneous Saccharification and Fermentation Process of Different Cellulosic Substrates Using a Recombinant Saccharomyces cerevisiae Harbouring the $\beta$-Glucosidase gene," Electronic Journal of Biotechnology, Vol. 13, No. 2, 2010, p. 1.

[11] J. H. Lee, R. J. Pagan and P. L. Rogers, "Continuous Simultaneous Saccharification and Fermentation of Starch using Zymomonas mobilis," Biotechnology and Bioengineering, Vol. 25, No. 3, 1983, pp. 659-669. 


\section{doi:10.1002/bit.260250304}

[12] H. Nellaiah, T. Karunakaran and P. Gunasekaran, "Ethanol Fermentation of Cassava Starch by Zymomonas mobilis NRRL B-4286,” Biomass, Vol. 15, No. 3, 1988, pp. 201-207. doi:10.1016/0144-4565(88)90085-6

[13] S. H. Krishna, T. J. Reddy and V. Chowdary, "Simultaneous Saccharification and Fermentation of Lignocellulosic Wastes to Ethanol Using a Thermotolerant Yeast,"
Bioresource Technology, Vol. 77, No. 2, 2001, pp. 193196. doi:10.1016/S0960-8524(00)00151-6

[14] Zs. Kadar, Zs. Szengyel and K. Reczey, "Simultaneous Saccharification and Fermentation (SSF) of Industrial Wastes for the Production of Ethanol," Industrial Crops and Products, Vol. 20, No. 1, 2004, pp. 103-110. doi:10.1016/j.indcrop.2003.12.015 